\title{
AN ASSOCIATION OF ENDOPLASMIC RECTICULUM WITH THE GOLGI APPARATUS IN GOLDEN HAMSTER SPERMATIDS
}

\author{
L. E. FRANKLIN \\ Delta Regional Primate Research Center, Tulane University, \\ Covington, Louisiana 70433, U.S.A.
}

(Received 26th October 1970)

\begin{abstract}
Summary. A lamella of granular endoplasmic reticulum was found to be associated with the outer surface of the Golgi apparatus of golden hamster spermatids during the period of acrosome production. The morphological situation during this period has some features in common with those reported in other cell types during the production of secretory granules, including lysosomes. Thus, the observations are compatible with the view that the acrosome is a specialized lysosome.

Stacked lamellae which resemble annulate lamellae were also found to be associated with the Golgi apparatus of some spermatids. The morphological variations observed are consistent with the possibility that annulate lamellae may in some cases undergo conversion into granular endoplasmic reticulum.
\end{abstract}

\section{INTRODUCTION}

The participation of the Golgi apparatus in the formation of the acrosome is well established (Bowen, 1922, 1924; Wilson, 1925; Burgos \& Fawcett, 1955; Glermont \& Leblond, 1955; Beams \& Kessel, 1968). In early spermatids of the dragonfly, Aeschna grandis, Kessel (1966) demonstrated a morphological relationship between a lamella of granular endoplasmic reticulum and the Golgi apparatus which could reflect participation of the endoplasmic reticulum in production of part of the acrosomal material. More recently, Sandoz (1968, 1970) described a similar relationship in mouse spermatids. The purpose of this report is to present morphological evidence of an association of granular endoplasmic reticulum, and of a membrane system resembling annulate lamellae with the Golgi apparatus during formation of the acrosome in spermatids of the golden hamster.

\section{MATERIALS AND METHODS}

After excision, the testes of adult golden hamsters were immersed and diced in a diluted preparation of the fixative solution devised by Karnovsky (1965). The composition of the diluted fixative was: $1.8 \%$ glutaraldehyde, $1.3 \%$ paraformaldehyde and $0.03 \%$ calcium chloride in $0.07 \mathrm{M}$-sodium cacodylate ( $\mathrm{pH} \mathrm{7.4)}$. After 4 to $5 \mathrm{hr}$, the specimens were transferred into $0.2 \mathrm{M}$-cacodylate buffer, 
chilled and stored overnight. The specimens were subsequently carried through three additional changes of buffer and post-fixed in $1.0 \%$ osmium tetroxide in $0 \cdot 1 \mathrm{M}$-buffer for $1 \mathrm{hr}$. After a brief rinse in buffer, the specimens were dehydrated in a graded series of ethanols and transferred into propylene oxide, then embedded in an Epon 812 epoxy resin mixture according to the recommendations of Luft (1961).

Sections of the embedded specimens were cut on either an LKB Ultratome I or a Sorvall MT-2 ultramicrotome, with a diamond knife (Rondkin Corp.). Contrast of the sectioned specimens was enhanced by staining first with $7.0 \%$ magnesium uranyl acetate (Frasca \& Parks, 1965) then lead citrate (Reynolds, 1963). The stained sections were viewed and photographed with either an RCA EMU-3G or Philips EM-300 electron microscope (by courtesy of the Institute of Molecular Evolution, University of Miami).

\section{OBSERVATIONS}

As the figures indicate, a lamella of endoplasmic reticulum lies adjacent to considerable portions of the outer or distal surface of the Golgi apparatus of golden hamster spermatids during the formation and enlargement of the acrosome. Although few in number, ribosomes are associated with the distal wall of the reticulum. In some instances, bleb-like projections of the wall of the reticulum adjacent to the Golgi surface are apparent (Pl. 1, Figs. 1, 2).

In several spermatids, stacks of two or more lamellae of endoplasmic reticulum which generally lack ribosomes overlie part of the Golgi surface (Pl. 2, Figs. 6, 7). Portions of the stacked lamellae often exhibit regularly spaced gaps and occasional annuli which are characteristic of annulate lamellae (Pl. 2, Figs. $6,7)$. In one case ( $\mathrm{Pl}$. 2, Fig. 8), an annulus was observed in the single layer of granular endoplasmic reticulum associated with the Golgi complex. Where stacked lamellae are observed, the innermost lamella appears to coincide with the single lamella of granular endoplasmic reticulum described in the preceding paragraph. However, membrane-associated ribosomes are not apparent within the stacked area.

\section{DISCUSSION}

Formation of the acrosome has until recently been linked almost exclusively to

\section{EXPLANATION OF PLATE 1}

FIG. 1. An early spermatid (the Golgi phase of spermiogenesis; Leblond \& Clermont, 1952). The spherical acrosome (AC) and associated Golgi complex (GC) are situated at the anterior pole of the nucleus $(\mathrm{N})$, of which a small portion is pictured in the lower right corner of the micrograph. A single lamella of endoplasmic reticulum overlies the distal surface of the Golgi complex. Four bleb-like expansions of the wall of the reticulum adjacent to the Golgi surface are indicated (arrows, B). The unlabelled arrow points to a small group of ribosomes adherent to the outer wall of the reticulum. Such areas are more clearly shown in subsequent figures. $\times 23,500$.

Figs. 2, 3 and 4. Three spermatids in the cap phase of spermiogenesis (Leblond \& Clermont, 1952). The unlabelled arrows indicate regions of the outer wall of the reticulum to which ribosomes are attached. A bleb-like expansion of the inner wall of the reticulum is indicated in Fig. 2 (arrow, B). Coated vesicles and a bleb-like expansion of the inner wall of a Golgi lamella are apparent in Fig. 4 (arrows, $\mathrm{C}$ ). AC-acrosome, $\mathrm{N}$-nucleus. Fig. 2, × 13,500; Fig. 3, ×22,000; Fig. 4, × 19,000. 
PLATE 1

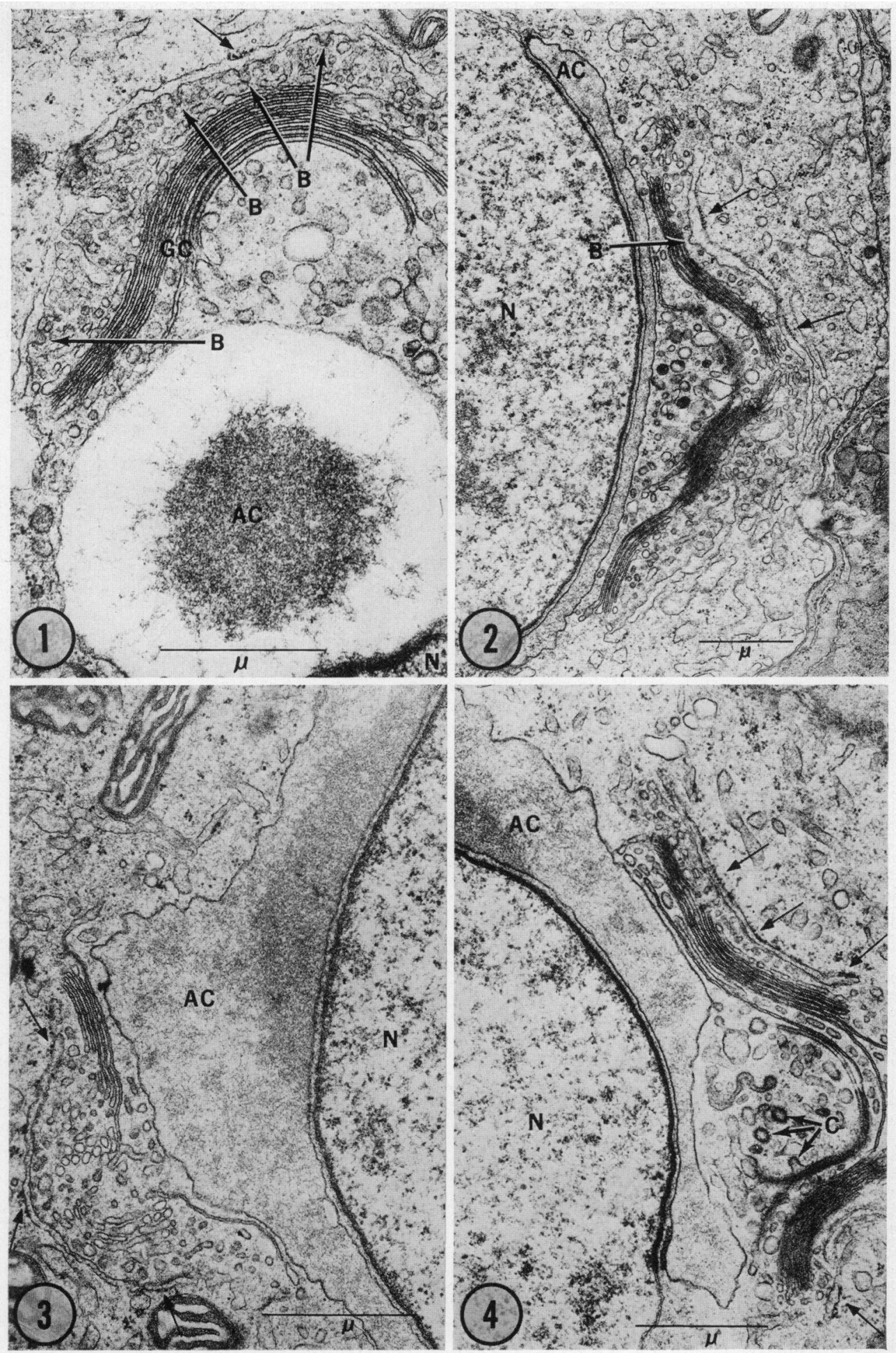


PLATE 2

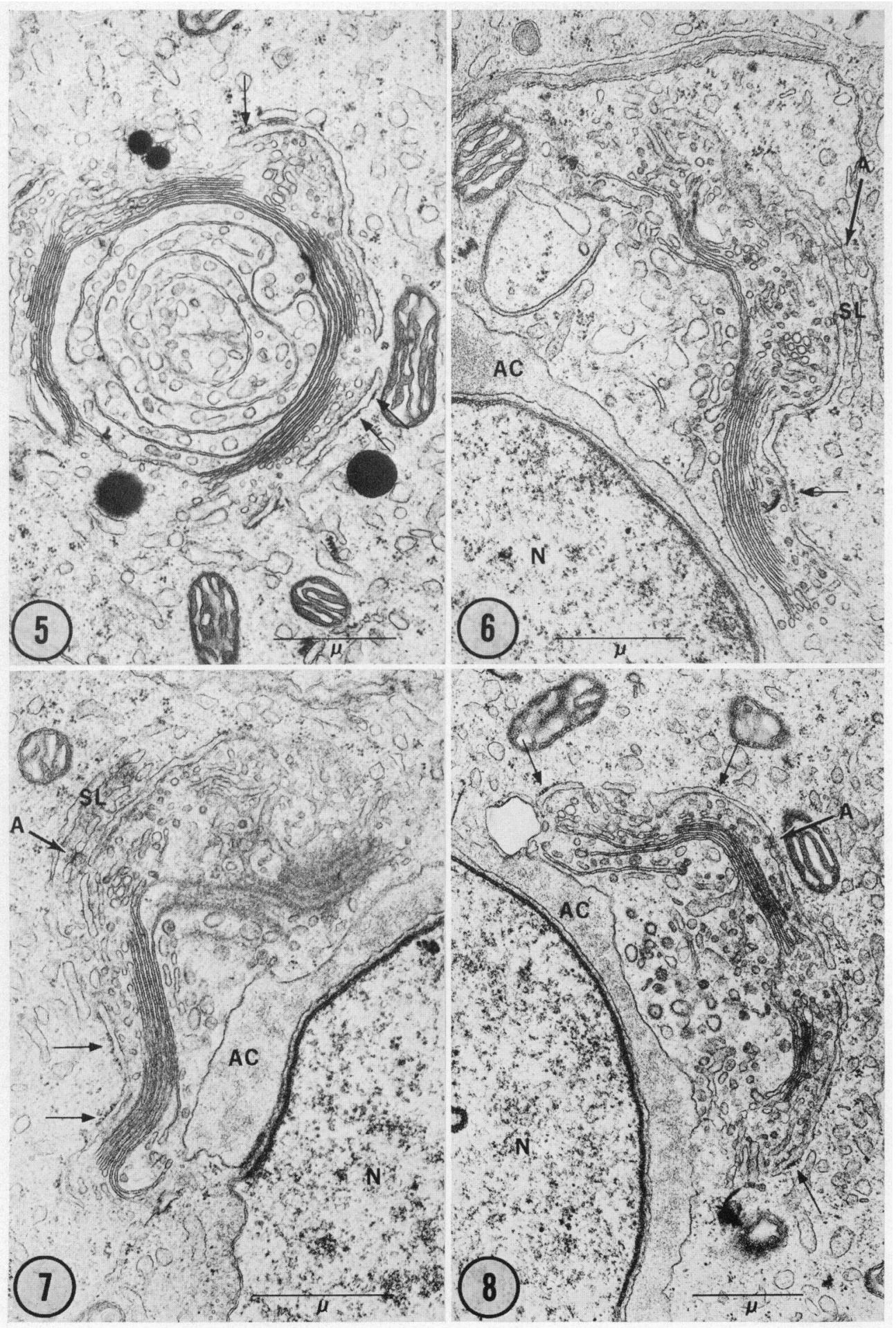

(Facing p. 69) 
activity of the Golgi apparatus. In 1966, Kessel observed a lamella of endoplasmic reticulum around the Golgi apparatus of early spermatids (and some spermatocytes, see Beams \& Kessel, 1968) of the dragonfly, Aschena grandis. Ribosomes were associated with the lamella but were generally absent from the wall of reticulum adjacent to the Golgi apparatus, and bleb-like expansions of that wall toward the Golgi apparatus were noted. Subsequently, Sandoz (1968) reported a similar association of endoplasmic reticulum with the Golgi apparatus in spermatids of the mouse, and followed the formation of the acrosome in detail in that species (Sandoz, 1970). The observations recorded here, like those of Sandoz $(1968,1970)$ add support to the possibility voiced by Kessel (1966) and Beams \& Kessel (1968) that the endoplasmic reticulum might participate in the production of part of the acrosomal material.

Several lysosomal as well as non-lysosomal enzymes have been extracted from mammalian spermatozoa (see Austin, 1960; Hathaway \& Hartree, 1963; Stambaugh \& Buckley, 1968, 1969; Allison \& Hartree, 1969, 1970; Dingle \& Dott, 1969; Srivastava, Zaneveld \& Williams, 1970). In most instances the enzymes appear to be extracted from acrosomes, but in bull spermatozoa for example, $\beta$-glucuronidase, acid phosphatase, acid protease and ribonuclease are concentrated in the residual cytoplasmic droplet (Dingle \& Dott, 1969). The identification of a variety of lysosomal enzymes in acrosomal fractions of spermatozoa led Allison \& Hartree $(1969,1970)$, in particular, to suggest that the acrosome represents a specialized lysosome.

Both the endoplasmic reticulum and the Golgi apparatus appear to be involved in the production of lysosomes (see Novikoff, Essner \& Quintana, 1964; Novikoff, 1967) and other protein-containing secretory granules such as the zymogen granules of acinar cells of the pancreas (see Palade, Siekevitz \& Caro, 1962; Beams \& Kessel, 1968). Thus, the morphological circumstances during acrosome production are consistent with the view that the acrosome is a special form of lysosome. The presence of lysosomal enzymes in the residual cytoplasmic droplet (see Dingle \& Dott, 1969) might also be expected since the organelles which produce the acrosome (endoplasmic reticulum-Golgi apparatus) subsequently migrate to the droplet.

Functions of annulate lamellae are largely speculative. According to Wisch-

\section{EXPLANATION OF PLATE 2}

Fig. 5. This figure depicts a 'transverse' plane of the Golgi apparatus of a spermatid which is presumed to be in the cap phase of spermiogenesis, judged by the developmental stages of other spermatids in the same segment of seminiferous tubule. Golgi lamellae surround the centre of the Golgi complex. A discontinuous lamella of endoplasmic reticulum lies adjacent to about half of the Golgi complex. The unlabelled arrows, as in the preceding figures, indicate groups of membrane-associated ribosomes. $\times 18,000$.

Figs. 6 and 7. Spermatids in the cap phase of spermiogenesis which show stacked lamellae (SL) at the Golgi surface. The stacked lamellae bear a resemblance to annulate lamellae as is evidenced by the presence of annuli (arrows, A). Note the anastomosing tubules of the Golgi apparatus at the top centre of Fig. 7. AC-acrosome, N-nucleus, unlabelled arrows-membrane-associated ribosomes. Fig. 6, × 19,000; Fig. 7, $\times 21,000$.

Fig. 8. Spermatid in the cap phase of spermiogenesis. This example shows an annulus (arrow, A) which has an appearance typical of annulate lamellae within the single lamella of granular endoplasmic reticulum which overlies the Golgi surface. AC-acrosome, $\mathrm{N}$-nucleus, unlabelled arrows-membrane-associated ribosomes. $\times 16,000$. 
nitzer (1970), such evidence as is available points toward a rôle in protein synthesis, the lamellae in some cases being capable of conversion to granular endoplasmic reticulum. The stacked lamellae which were observed at the Golgi surface of a few spermatids did show occasional annuli and could reflect transition of annulate lamellae to granular reticulum. Indeed, an annulus is evident in the lamella of endoplasmic reticulum adjacent to the Golgi surface in Pl. 2, Fig. 8, and also pictured by Sandoz (1970) in the mouse.

Of the more interesting speculations about possible functions of annulate lamellae, one that stems largely from their nuclear envelope origin is that the lamellae might transport nuclear information to remote regions of the cytoplasm and thereby exercise nuclear control over synthetic activities in those regions (see Kessel, 1968). In any event, stacked lamellae which resemble annulate lamellae are associated in some instances with the Golgi apparatus while it is still in the vicinity of the acrosome.

\section{Note added in proof}

The evolution of the Golgi apparatus during spermiogenesis in the rat was recently followed in detail by Susi, Leblond \& Clermont (1971, Am. F. Anat. $130,151)$ who employed a periodic acid-silver technique to localize glycoprotein, as well as routine electron microscopical techniques. The study clearly demonstrated an association of a layer of cisternae of endoplasmic reticulum with the peripheral surface of the Golgi apparatus during production of the acrosome.

\section{AGKNOWLEDGMENTS}

Financial support for this study was provided by NIH Contract 69-2101, NIH Grant HD-04233, and NIH Grant RR 00164-09. I wish to express appreciation to Mr E. N. Fussell, Miss Christine Weaver and Miss Charlotte Hooks for technical assistance, and to Mrs Nelwyn Hollenshead for secretarial assistance.

\section{REFERENGES}

Allison, A. G. \& Hartree, E. F. (1969) Lysosomal nature of the acrosomes of ram spermatozoa. Biochem. 7. 111, 35P.

Allison, A. C. \& Hartree, E. F. (1970) Lysosomal enzymes in the acrosome and their possible rôle in fertilization. 7. Reprod. Fert. 21, 501 .

Austin, C. R. (1960) Gapacitation and the release of hyaluronidase from spermatozoa. $\mathcal{F}$. Reprod. Fert. $1,310$.

Beams, H. W. \& Kessel, R. G. (1968) The Golgi apparatus : structure and function. Int. Rev. Cytol. 23, 260.

Bowen, R. H. (1922) On the idiosome, Golgi apparatus, and acrosome in the male germ cells. Anat. Rec. 24, 159.

Bowen, R. H. (1924) On the acrosome of the animal sperm. Anat. Rec. $28,1$.

Burgos, M. H. \& FawcetT, D. W. (1955) Studies on the fine structure of the mammalian testis. I. Differentiation of the spermatids in the cat (Felis domestica). 7 . biophys. biochem. Cytol. 1, 287.

Clermont, Y. \& Leblond, C. P. (1955) Spermiogenesis of man, monkey, ram and other mammals as shown by the "periodic acid-Schiff" technique. Am. 7. Anat. 96, 229.

Dingle, J. T. \& DotT, H. M. (1969) Lysosomal enzymes in bull and ram semen. Biochem. 7. 111, 35P.

Frasca, J. M. \& PARKs, V. R. (1965) A routine technique for double-staining ultrathin sections using uranyl and lead salts. 7. Cell Biol. 25, 157.

Hathaway, R. R. \& Hartree, E. F. (1963) Observations on the mammalian acrosome: experimental removal of acrosomes from ram and bull spermatozoa. F. Reprod. Fert. 5, 225.

KARNovsky, M. H. (1965) A formaldehyde-glutaraldehyde fixative of high osmolality for use in electron microscopy. 7. Cell Biol. 27, 137A. 
KesseL, R. G. (1966) The relationship between the endoplasmic reticulum and the Golgi complex in spermatids of the dragonfly. 7. Cell Biol. 31, 148A.

Kessel, R. G. (1968) Annulate lamellae. F. Ultrastruct. Res. Suppl. 10, 1.

Leblond, C. P. \& Clermont Y. (1952) Spermiogenesis of rat, mouse, hamster and guinea pig as revealed by the "periodic acid-fuchsin sulfurous acid" technique. Am. F. Anat. 90, 167.

Lurr, J. H. (1961) Improvements in epoxy resin embedding methods. F. biophys. biochem. Cytol. 9, 409.

NoviKorf, A. B. (1967) Lysosomes in nerve cells. In: The Neuron p. 319. Ed. H. Hyden. Elsevier, Amsterdam.

Novikorf, A. B., Essner, E. \& Quintana, N. (1964) Golgi apparatus and lysosomes. Fedn Proc. Fedn Am. Socs exp. Biol. 23, 1010.

Palade, G. E., Stekevitz, P. \& Garo, L. G. (1962) Structure, chemistry and function of the pancreatic exocrine cell. In: Giba Foundation Symposium on Exocrine Pancreas, Normal and Abnormal Functions, p. 23. Eds. A. V. S. de Reuck and M. P. Cameron. Churchill, London.

Reynords, E. S. (1963) The use of lead citrate at high $\mathrm{pH}$ as an electron-opaque stain in electron microscopy. 7. Cell Biol. 17, 208.

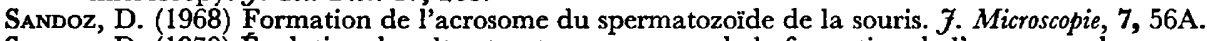

SANDOZ, D. (1970) Evolution des ultrastructures au cours de la formation de l'acrosome du spermatozoïde chez la souris. 7. Microscopie, 9, 535.

Srivastava, P. N., Zaneveld, L. J. D. \& Williams, W. L. (1970) Mammalian sperm acrosomal neuraminidases. Biochem. biophys. Res. Comm. 39, 575.

Stambaugh, R. \& Buckley, J. (1968) Zona pellucida dissolution enzymes of the rabbit sperm head. Science, N.Y. 161, 585.

Stambaugh, R. \& BuCKLEY, J. (1969) Identification and subcellular localization of the enzymes effecting penetration of the zona pellucida by rabbit spermatozoa. F. Reprod. Fert. 19, 423.

Wirson, E. B. (1925) The cell in development and heredity, 3rd edn, p. 382. Macmillan, New York.

Wischnitzer, S. (1970) The annulate lamellae. Int. Rev. Cytol. 27, 65. 